\title{
Heat and humidity features and energy saving potential of temperature and humidity independent control air-conditioning system using refrigerant mixture
}

\author{
Pengfei $\mathrm{Yu}^{1,2^{*}}$, Xiaosong Zhang ${ }^{1}$ \\ ${ }^{1}$ School of Energy and Environment, Southeast University, Nanjing 210096, China \\ ${ }^{2}$ College of Energy and Power Engineering, Nanjing Institute of Technology, Nanjing 211167, China
}

Corresponding Author Email: 230119636@seu.edu.cn

https://doi.org/10.18280/ijht.360242

Received: 3 October 2017

Accepted: 25 February 2018

\section{Keywords:}

coefficient of performance (COP), temperature and humidity independent control (THIC), double evaporating temperature (DET) chiller

\begin{abstract}
This paper attempts to disclose the advances of zeotropic refrigerant mixture R236fa/R32 over the traditional refrigerants and the energy-saving mechanism of the DCS-THIC AC system. For this purpose, the physical and thermodynamic properties of R236fa/R32, R22, R410A, $\mathrm{R} 407 \mathrm{C}$ and R134a refrigerants were compared, and the performance of R236fa/R32 refrigeration system was investigated on a $4.0 \mathrm{~kW}$ double evaporating temperature (DET) chiller, which applies to the temperature and humidity independent control (THIC) AC system. The results show that the $\mathrm{R} 236 \mathrm{fa} / \mathrm{R} 32$ refrigerant mixture can save more energy than the traditional refrigerates. When the mass fraction of R32 reaches $60 \%$, the coefficient of performance (COP) of R236fa/R32 refrigerant mixture peaks at 4.55, and the compressor power is minimized at $1.2 \mathrm{~kW}$. In addition, the humidity control effect and fresh air volume of the THIC AC system with dual cooling sources (DCS-THIC AC) in four operating modes were compared to the traditional AC system in three operating modes. The comparison reveals that the DCS-THIC AC system using R236fa/R32 (0.4/0.6) refrigerator mixture saves more energy than the AC system using pure R22. Particularly, the energy efficiency can be improved by $27.22 \%$ by the DCS-THIC AC system in Mode 4. The research findings shed new light on the energy conservation of AC system in hot summer and cold winter region.
\end{abstract}

\section{INTRODUCTION}

The energy conservation of air conditioning (AC) system hinges on the use of green refrigerant with good circulation performance. Different AC systems have adopted varied methods to improve the performance of the refrigerant. For instance, the temperature and humidity independent control (THIC) AC system removes the latent load from the total load, thus enhancing the coefficient of performance (COP) of the chiller [1].

Over the years, much research has been done at home and abroad on different AC systems and their refrigeration units. For example, Gao et al. [2] quantified the effects of such factors as cooling water parameters and indoor air temperature on the cooling capacity of radiant cooling system. Khan et al. [3] proved that radiant cooling system consumes $17.5 \%$ fewer energy than the traditional all-air system. Si et al. [4] verified the feasibility of a new all-air supplied induction radiant AC system using zeotropic refrigerant. Zhao et al. [5] proposed and tested a new household variable refrigerant flow (VRF) radiant $\mathrm{AC}$ system for air cooling and humidity control. Han et al. [6] developed two THIC AC systems for indoor temperature control and humidity control, respectively.

Yao et al. [7] put forward an AC system with lowtemperature and low-concentration liquid desiccant, which uses the condenser heat to regenerate the refrigerant solution. Zhao et al. [8] created a heat pump-driven THIC system consisting of an air dehumidifier and a dry fan coil. Jeong et al. [9] explored the effect of the low-temperature dehumidification wheel in the wheel dehumidification AC system. Su et al. [10] combined compression and absorption type refrigeration with liquid dehumidification $\mathrm{AC}$ into a united humidity control AC system. Jiang et al. [11] experimentally investigated a new mixed solid dehumidification heat pump system.

The above studies share some common defects. In traditional AC systems, sensible and latent loads are handled simultaneously, leading to a low COP of the chiller. This is because the air must be cooled at a temperature below the dew point to allow condensation [12-13]. Moreover, the THIC AC system fails to achieve a desirable dehumidification effect, as liquid desiccants are prone to corrosion [14] while solid desiccants require a high temperature for regeneration and a large storage space for adsorbents [15].

To overcome these defects, a viable option lies in the THIC AC system using zeotropic refrigerant mixture [16-18]. Liu et al. [19-21] probed deep into the double evaporating temperature (DET) chiller of a THIC AC system, which contains two evaporators, one compressor and one condenser. In the system, the R236fa/R32 refrigerant mixture is adopted to adjust the temperature of the chilled water to $7^{\circ} \mathrm{C}$ and $18^{\circ} \mathrm{C}$ to treat the sensible and latent heats. However, the following questions remain unanswered in the existing research: what are the advantages of zeotropic refrigerant mixture $\mathrm{R} 236 \mathrm{fa} / \mathrm{R} 32$ over the traditional refrigerants (e.g. R22, R410A, $\mathrm{R} 407 \mathrm{C}$ and R134a)? what is the energy-saving mechanism of the DCS-THIC AC system?

To answer these questions, this paper carries out several experiments on a $4.0 \mathrm{~kW}$ DET chiller using different refrigerants, and establishes a design calculation model for 
THIC AC system. Then, the cooling capacity and fresh air volume were investigated to evaluate the energy consumption in each of the four modes of THIC AC system with dual cooling sources (DCS-THIC AC). The said system was compared with three traditional AC systems in terms of the energy-saving potential.

\section{EXPERIMENTAL ANALYSIS}

\subsection{Refrigerant parameters}

The main physical parameters of each refrigerant are listed in Table 1. The phase change characteristics of the refrigerant are calculated by REFPROP 8.0 software. The DET was achieved thanks to the large temperature glide of R236fa/R32 mixture. The two refrigerants differ in boiling point and freezing point. In particular, R32 boasts a high unit cooling capacity. When mixed together, the R236fa/R32 has a moderate critical temperature, a low ozone depletion potential (ODP) and a small global warming potential (GWP).

The saturated vapor pressure directly bears on the cooling performance of the AC system. As shown in Figure 1, R410A has the highest saturated vapor pressure, about $60 \%$ higher than that of R22 and 76\% higher than that of R134. Both $\mathrm{R} 407 \mathrm{C}$ and R236fa/R32 are zeotropic mixtures with temperature glide. In terms of saturated vapor pressure, $\mathrm{R} 407 \mathrm{C}$ and $\mathrm{R} 236 \mathrm{fa} / \mathrm{R} 32$ are respectively $14 \%$ and $17 \%$ higher than R22. Overall, R236fa/R32 enjoys a moderate working pressure.

Table 1. Main physical parameters of each refrigerant

\begin{tabular}{|c|c|c|c|c|c|c|c|c|}
\hline Refrigerant & $\begin{array}{c}\text { Boiling point } \\
{ }^{\circ} \mathrm{C}\end{array}$ & $\begin{array}{c}\text { Freezing point } \\
/{ }^{\circ} \mathrm{C}\end{array}$ & $\begin{array}{l}\text { Critical temperature } \\
\qquad /{ }^{\circ} \mathrm{C} \\
\end{array}$ & $\begin{array}{c}\text { Critical pressure } \\
/ \mathrm{Mpa}\end{array}$ & $\begin{array}{c}\text { Latent heat } \\
/ \mathrm{KJ} / \mathrm{kg}\end{array}$ & ODP & GWP & $\begin{array}{c}\text { Safety } \\
\text { level }\end{array}$ \\
\hline R22 & -40.82 & -160 & 96.15 & 4.75 & 233.5 & 0.045 & 1700 & A1 \\
\hline $\mathrm{R} 407 \mathrm{C}$ & -43.6 & -115 & 86.74 & 4.619 & 249.9 & 0 & 1526 & A1 \\
\hline R410A & -51.6 & -155 & 72.5 & 4.95 & 256.7 & 0 & 1975 & A1 \\
\hline $\mathrm{R} 134 \mathrm{a}$ & -26.1 & -103 & 101.1 & 4.066 & 216 & 0 & 1300 & A1 \\
\hline R236fa & -1.4 & -93.6 & 124.9 & 3.2 & 106.24 & 0 & 6300 & A1 \\
\hline R32 & -51.7 & -136 & 78.2 & 5.8 & 390.5 & 0 & 675 & $\mathrm{~A} 2$ \\
\hline
\end{tabular}

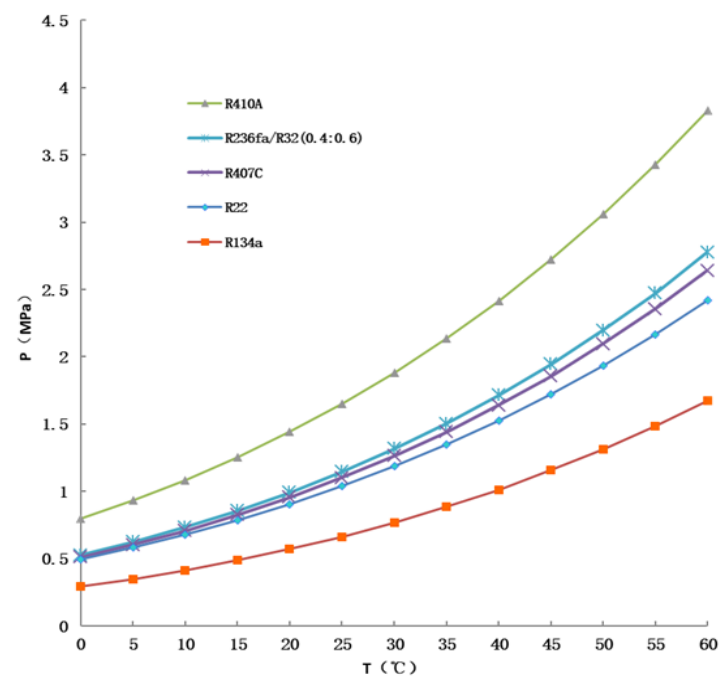

Figure 1. Saturated vapor pressure of each refrigerant

\subsection{Experimental research}

The test system and DET chiller are illustrated in Figure 2. It can be seen that the DET chiller consists of a compressor, a condenser, and expansion valve and two evaporators. The whole refrigeration system works in the following steps: First, the refrigerant mixture enters the compressor, releases heat in the condenser, and then reaches the expansion valve; Next, the refrigerant mixture evaporates in the low-temperature evaporator, producing low-temperature chilled water; After that, the mixture moves through the high-temperature evaporator, and evaporates again to create high-temperature chilled water; Then, the mixture is sucked into the compressor to start a new cooling cycle. Besides the DET chiller, the test system also includes a cooling water circulation system and two chilled water circulation systems. The water temperature is controlled by adjusting an electric heater and a water flow valve.
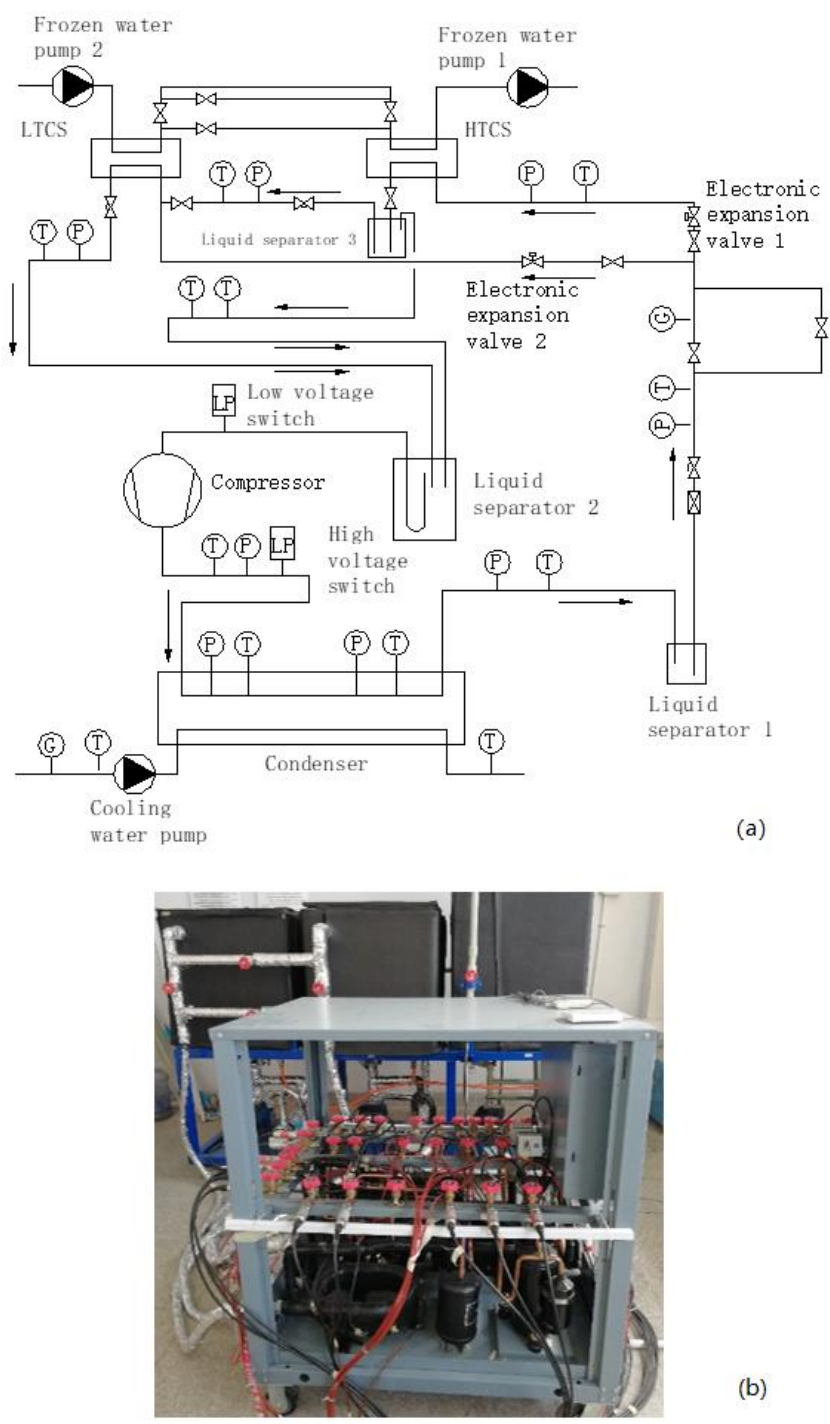

(b) 


\subsection{Refrigeration performance of $\mathrm{R} 236 \mathrm{a} / \mathrm{R32}$}

As shown in Figure 3, the COP of R236fa/R32 refrigerant mixture increased first and then decreased with the growth of R32 content and peaked at 4.55 when the R32 reached the mass fraction of $60 \%$. This trend can be explained as follows.

The compressor consumed a small amount of power because the isentropic curve of pure R236fa gas zone is relatively steep; with the slight increase of R32 content, the latent heat and refrigeration quantity were both on the rise.

When R236fa dominated the mixture, the isentropic curve of the zeotropic mixture had a large slope. In this case, the power consumption of the compressor was low and the COP was relatively high.

With the increase of R32, whose isentropic slope is very small, the COP of the refrigerant mixture declined because the growth of cooling capacity did not compensate for the soaring power consumption of the compressor.

In addition, the condensing and evaporating pressure increased with R32 component, while the compressor power decreased first then increased. The compressor power reached the minimum of $1.2 \mathrm{~kW}$ when the mass fraction of $\mathrm{R} 32$ was $60 \%$ in the mixture.

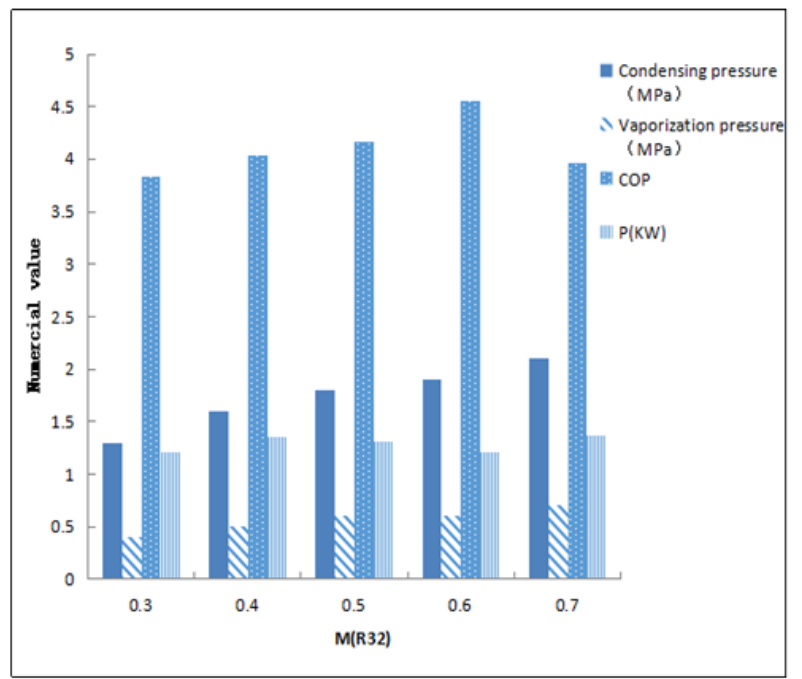

Figure 3. Performance of R236a/R32 refrigerant mixture in one cycle

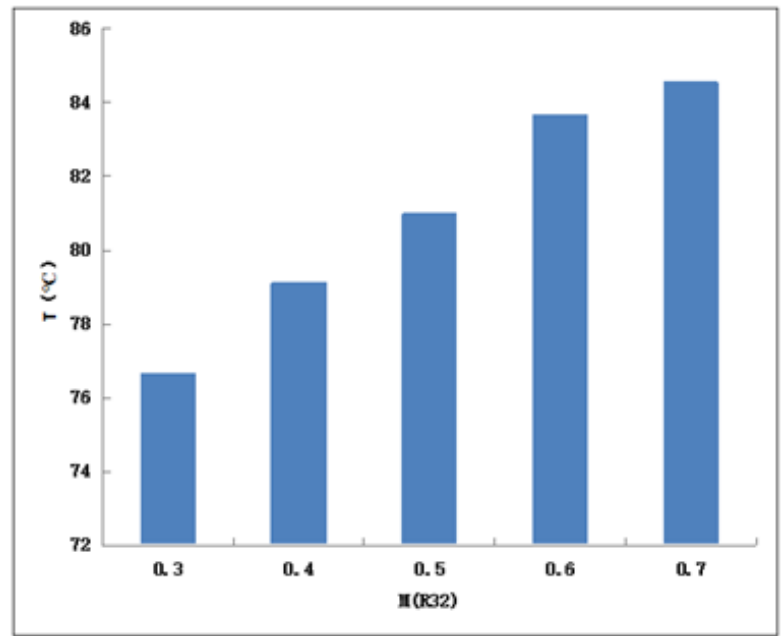

Figure 4. Exhaust temperature of R236a/R32 refrigerant mixture in one cycle
As can be seen from Figure 4, the exhaust temperature continued to rise with the increase of $\mathrm{R} 32$ content. The highest exhaust temperature was below $100^{\circ} \mathrm{C}$, which fulfils the requirements for the safe and stable operation of the compressor.

\subsection{Contrast against traditional refrigerants}

Figure 5 shows that R236fa/R32 refrigerant mixture outperformed all the traditional refrigerants (i.e. R22, R410A, $\mathrm{R} 407 \mathrm{C}$ and R134a) in the COP and compressor power. Moreover, the R410A achieved the highest condensing and evaporating pressure.

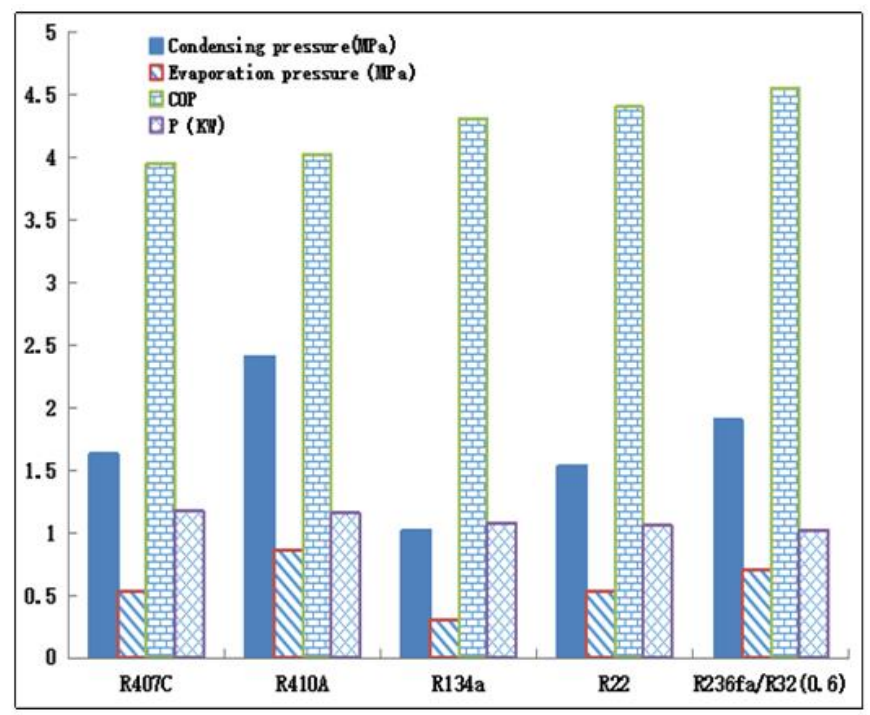

Figure 5. Performance of different refrigerants in one cycle

As shown in Figure 6, the highest and lowest exhaust temperatures respectively belong to R134a and R236fa/R32 refrigerant mixture.

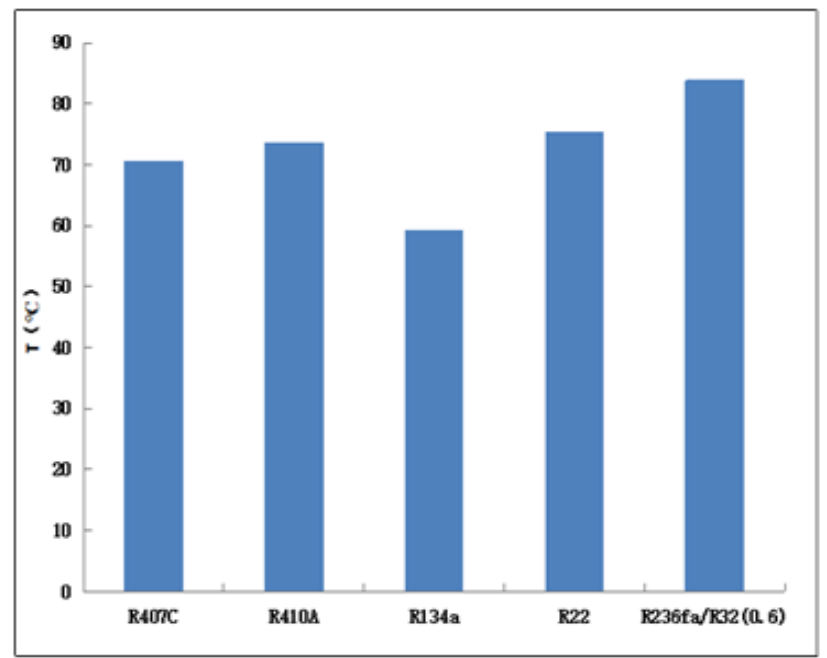

Figure 6. Exhaust temperature of different refrigerants in one cycle

\section{ENERGY CONSUMPTION ANALYSIS}

To identify the energy-saving potential of R236fa/R32 DCS-THIC AC system, four typical THIC modes were 
presented with or without fresh air, and the high-temperature cooling source (HTCS) and low-temperature cooling source (LTCS) energy consumptions were evaluated for each mode. Then, the R236fa/R32 (0.4/0.6) DCS-THIC AC system was compared with three traditional R22 AC systems.

\subsection{THIC modes}

Four THIC modes were summed up for DCS-THIC AC system, including Mode 1 (without fresh air), Mode 2 (with fresh air), Mode 3 (primary return air without precooling) and Mode 4 (primary return air with precooling) (Figure 7).

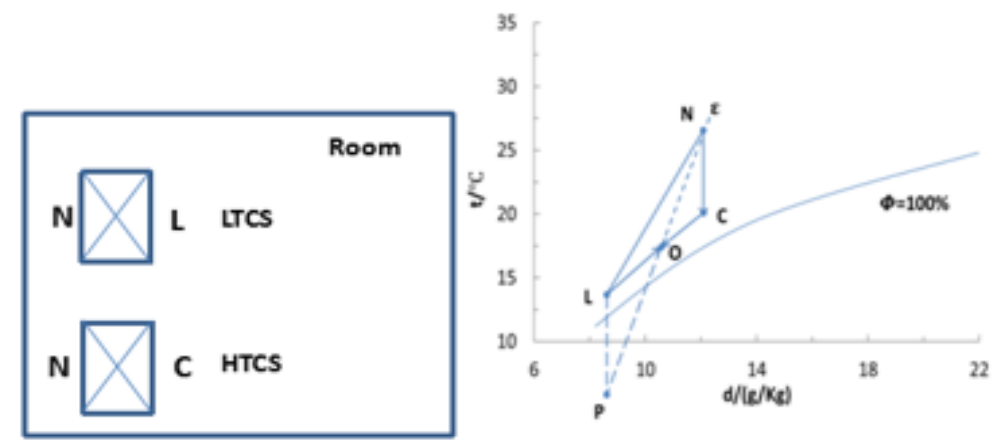

(a)
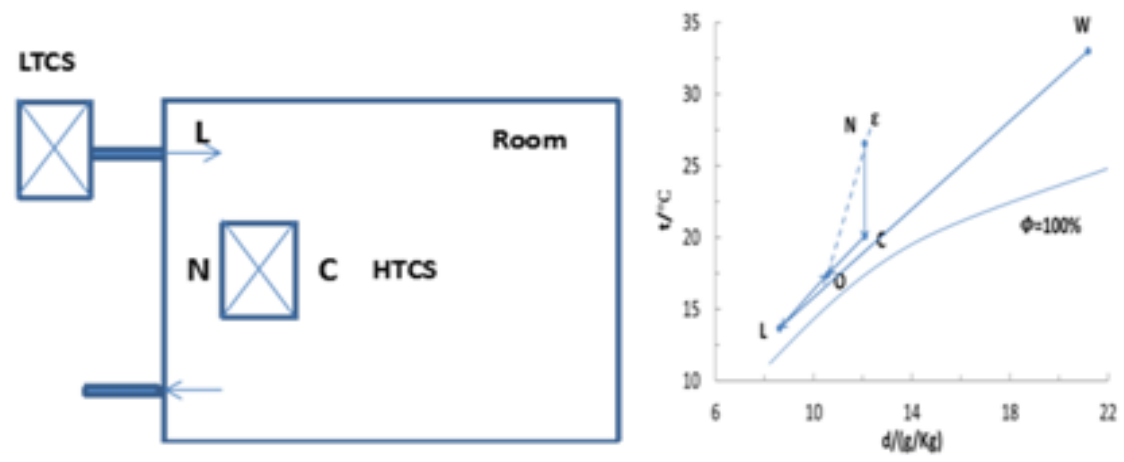

(b)
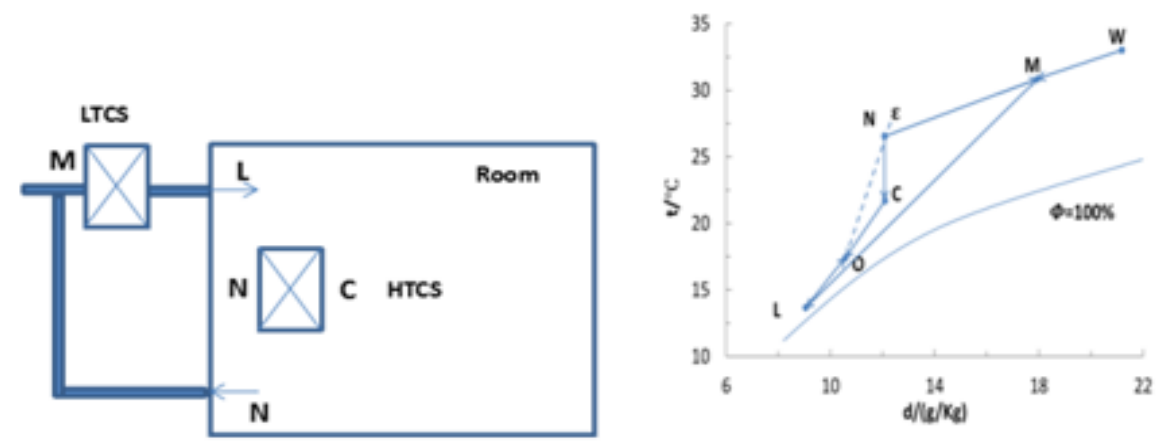

(c)
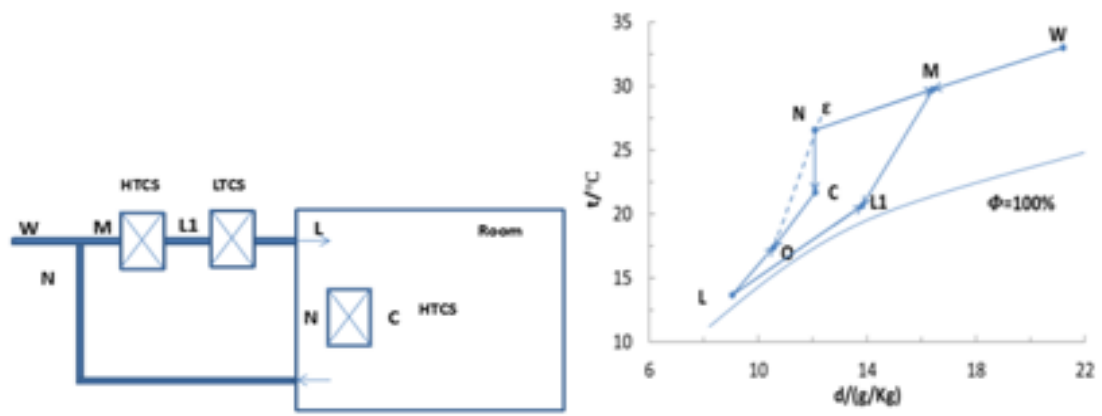

(d)

Figure 7. (a) Mode 1 (b) Mode 2 (c) Mode 3 (d) Mode 4

In Mode 1, the system does not require any fresh air, and controls humidity by return air only. Specifically, a part of the return air is cooled and dehumidified to the dew point (state L) to remove the latent load, while the other part is cooled to state $\mathrm{C}$ to remove the sensible load. The two states are mixed into the supplied air state $\mathrm{O}$ located on the heat moisture ratio $(\varepsilon)$ line of the air-conditioned space.

In Mode 2, the system requires fresh air, and relies on it to control the humidity. Specifically, a part of the fresh air is cooled and dehumidified to the dew point (state L) to remove the latent load, while the other part is cooled to state $\mathrm{C}$ to remove the sensible load.

In Mode 3, the system requires the primary return air, and mixes it with the fresh air to control humidity. The part of return air for humidity control in Mode 1 is replaced by the same amount of fresh air. The fresh air is processed by the 
sufficient cooling capacity of the LTCS.

In Mode 4, the system requires the primary return air with precooling. The mixture between the primary return air and the fresh air are precooled from state M to state L1, and further cooled and dehumidified to state L by the LTCS. The rest of the handling process is the same as Mode 3.

\subsection{Design and calculation models of TC-THIC AC}

Unlike traditional AC systems, the DCS-THIC AC focuses on humidity control through separation of heat load and moisture load (the basis for design calculation). Therefore, the sensible and latent heat loads must be classified and identified during the load calculation. The sensible heat load can be determined by the difference between the air supply temperature and the designed indoor temperature. Figure 8 illustrates the calculation process of the performance parameters, and Table 2 lists the design and calculation models.

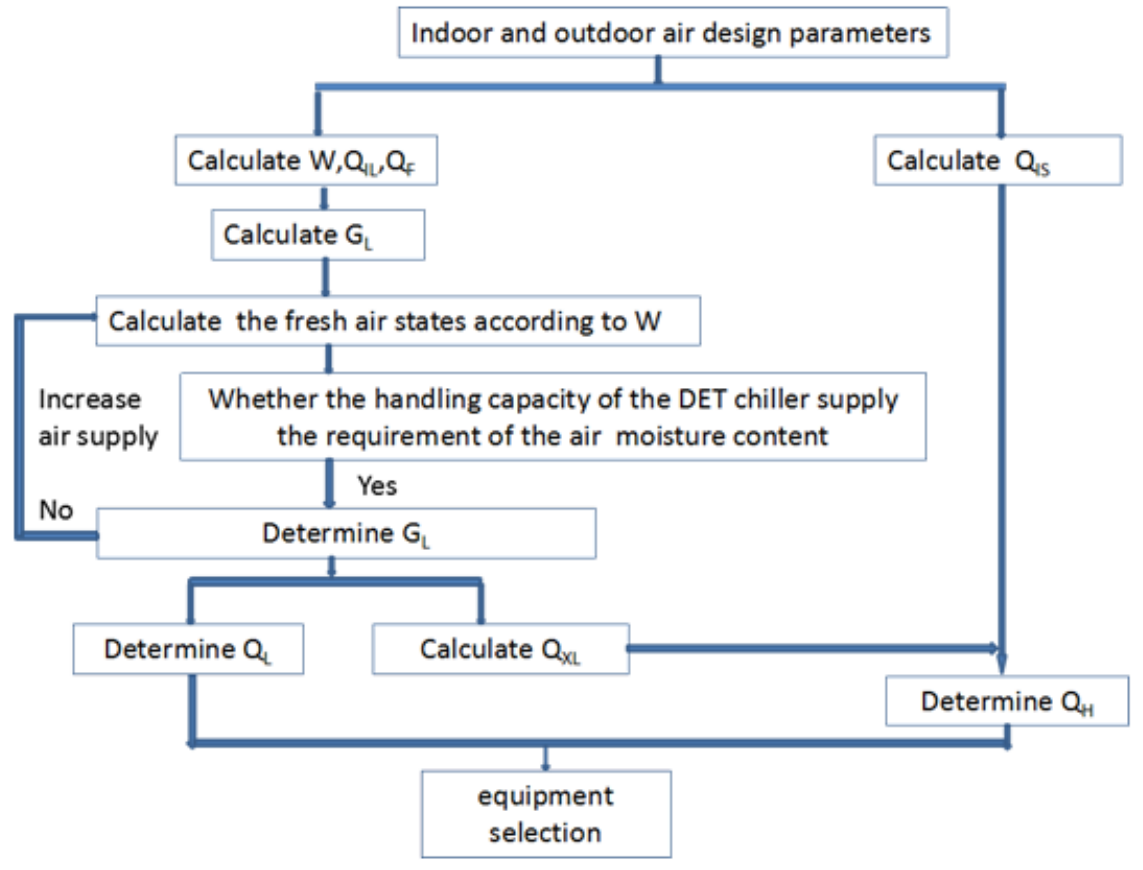

Figure 8. Calculation process of the performance parameters

Table 2. Design and calculation models of DCS-THIC AC

\begin{tabular}{|c|c|c|c|c|c|}
\hline Mode & $\begin{array}{c}\text { Air } \\
\text { supply }\end{array}$ & $\begin{array}{l}\text { Composition of Load processed by } \\
\text { the LTCS }\end{array}$ & $\mathrm{QL}_{\mathrm{L}}(\mathrm{w})$ & $\begin{array}{l}\text { Composition of Load } \\
\text { processed by the HTCS }\end{array}$ & $\mathrm{Q}_{\mathrm{H}}(\mathrm{w})$ \\
\hline $\begin{array}{l}\text { DCSTHIC } \\
\text { mode } 1\end{array}$ & \multirow{4}{*}{$G_{L}=\frac{\pi}{d_{n}-d_{L}}$} & $Q_{L}=Q_{I L}+Q_{X S}$ & $Q_{L}=G_{L} \frac{i_{n}-i_{L}}{3600}$ & & \\
\hline $\begin{array}{l}\text { DCSTHIC } \\
\text { mode } 2\end{array}$ & & \multirow{2}{*}{$Q_{L}=Q_{I L}+Q_{X S}+Q_{F S}+Q_{F L}$} & $Q_{L}=G_{L} \frac{i_{W}-i_{L}}{3600}$ & $Q_{L}=Q_{I S}-Q_{X S}$ & $Q_{H}=Q_{T}-Q_{X L}=G_{F} \frac{i_{n}-i_{C}}{3600}$ \\
\hline $\begin{array}{l}\text { DCSTHIC } \\
\text { mode } 3\end{array}$ & & & $Q_{L}=G_{L} \frac{i_{m}-i_{L}}{3600}$ & & \\
\hline $\begin{array}{l}\text { DCSTHIC } \\
\text { mode } 4\end{array}$ & & $Q_{L}=Q_{I L}+Q_{X S}+Q_{F S}+Q_{F L}-Q_{Y L}$ & $Q_{L}=G_{L} \frac{i_{L 1}-i_{L}}{3600}$ & $Q_{L}=Q_{I S}-Q_{X S}+Q_{Y L}$ & $Q_{H}=Q_{T}-Q_{X L}+Q_{Y L}=G_{F} \frac{i_{n}-i_{c}}{3600}$ \\
\hline
\end{tabular}

First, the maximum air supply rate was selected according to the sanitary and humidity control standards [22]. The air supply rate for humidity control was the circulating air rate provided by the LTCS in Mode 1, the fresh air rate in Mode 2, and the mixed air rate in Modes 3 and 4. Then, the load provided by the LTCS in Mode 1 consists of the indoor latent load and the sensible load provided by the LTCS $\left(Q_{x s}\right)$. The latter can be expressed as:

$Q_{X S}=c G_{L}\left(t_{n}-t_{L}\right) / 3600$

In Modes 2 and 3, the load provided by the LTCS includes the indoor latent load, the sensible load provided by the LTCS, the sensible load of the fresh air and the latent load of the fresh air. In Mode 4, the load provided by the LTCS covers the indoor latent load, the sensible load provided by the LTCS, the sensible load of the fresh air, and the latent load of the fresh air, excluding the precooling fresh air rate provided by the HTCS.

Moreover, the load provided by the HTCS in Modes 1, 2 and 3 equals the difference between the indoor sensible load and the sensible load provided by the LTCS. In Mode 4, the load provided by the HTCS includes the indoor sensible load and the precooling fresh air rate, excluding the sensible load provided by the LTCS.

\subsection{THIC modes of traditional AC systems}

The air handling process of traditional AC fall into three main categories: without fresh air (Mode 1), with fresh air (Mode 2) and primary return air without precooling (Mode 3). 

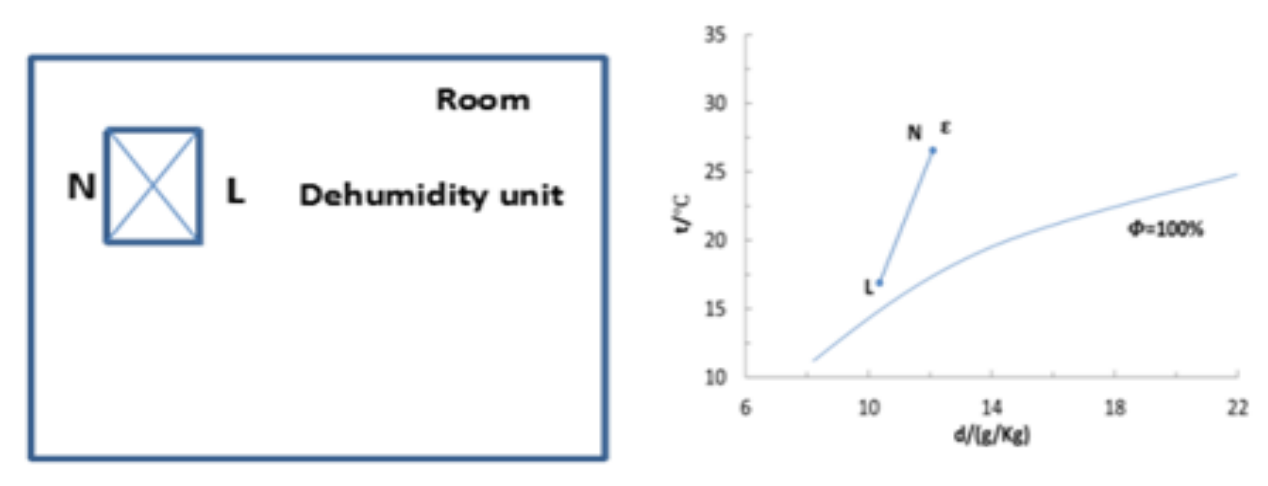

(a)
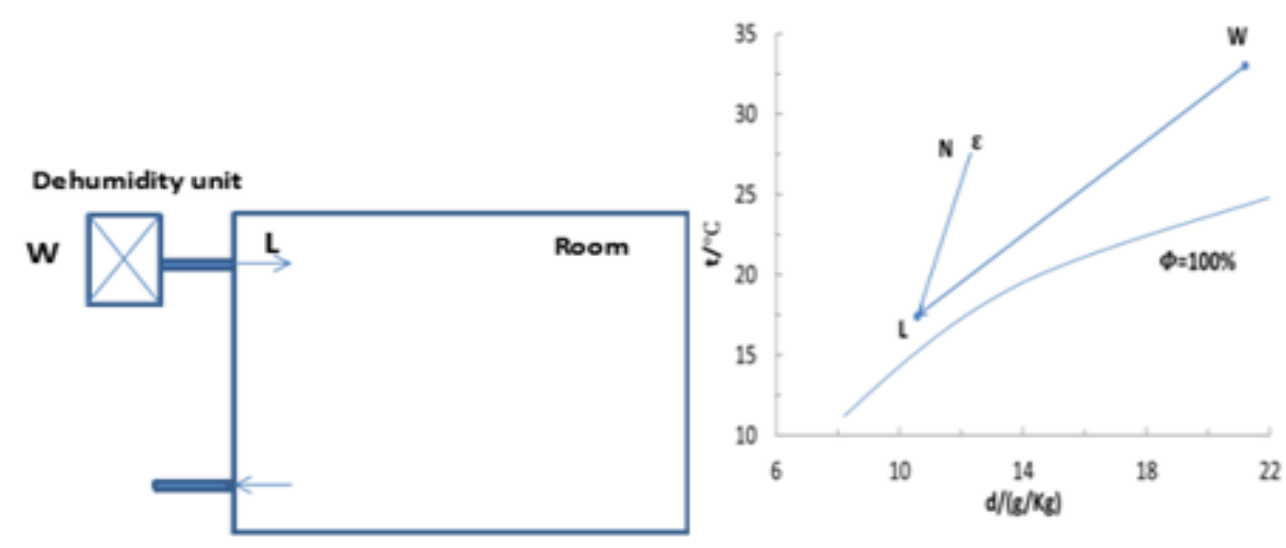

(b)
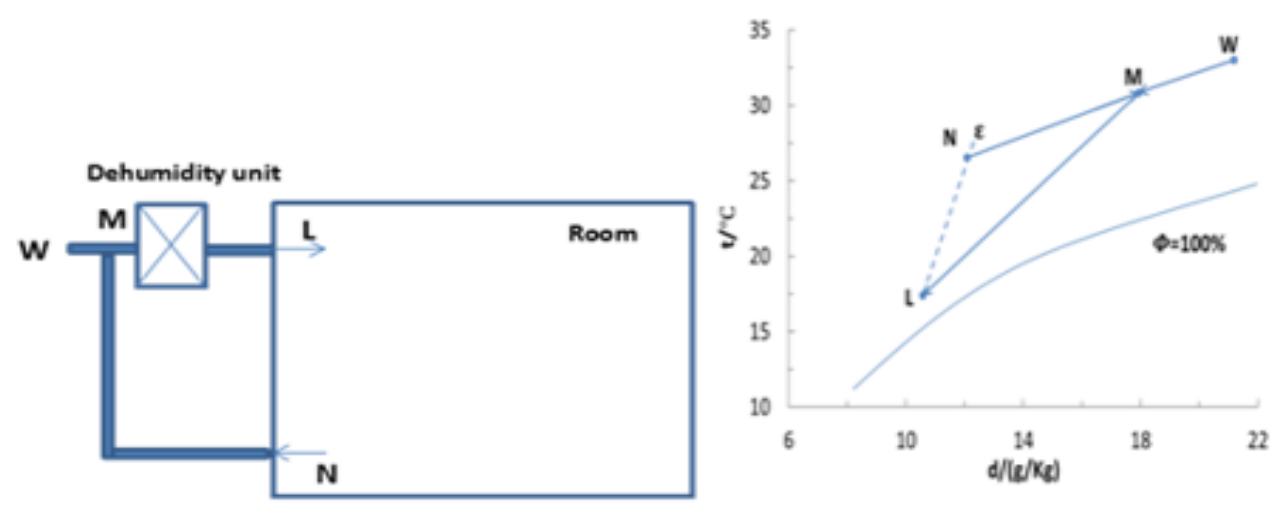

(c)

Figure 9. (a) Mode 1 (b) Mode 2 (c) Mode 3

\subsection{Energy efficiency of the DCS-THIC AC system}

Each type of AC system has its own energy consumption level. However, this level cannot directly reflect the energysaving features of the system, owing to the difference in refrigeration units. Instead, these features can be demonstrated by the energy efficiency ratio (EER) of the AC system. Cooling sources, pumps and fans are the main energy consumers in the system [23-24].

$E E R=\frac{Q}{\sum P_{i}}$

$P_{s}=P_{1}+P_{2}+P_{3}$

$P_{1}=P_{L}+P_{H}$

$P_{1}=\frac{Q_{L}}{C O P 1}+\frac{Q_{H}}{C O P 2}$

$P_{3}=\sum Q \times P_{f}$

where $\mathrm{K}$ is the water flow rate through the pump; $\mathrm{H}$ is the total head of the pump; $\eta$ is the pump efficiency; $P_{f}$ is the energy consumption of fans per water flow rate for the cooling tower.

\subsection{Case study}

The study area is a $20 \mathrm{~m}^{2}$ shop in Nanjing, a Chinese city in the hot summer and cold winter region. The parameters are configured as follows: cooling load $=2,800 \mathrm{~W}$; fresh air rate $=20 \mathrm{~m}^{3} / \mathrm{h} /$ person; occupant density $=4 \mathrm{~m}^{2} /$ person; moisture diffusion rate $=109 \mathrm{~g} / \mathrm{h} /$ person; indoor temperature $=26^{\circ} \mathrm{C}$; indoor relative humidity $=60 \%$; outdoor dry-bulb temperature $=34.8^{\circ} \mathrm{C}$, and outdoor wet-bulb temperature $=28.1^{\circ} \mathrm{C}$. The results of cooling source, air volume, power consumption and EER of each AC mode are recorded in Table 3 below. The following phenomena can be observed from these results. 
Table 3. Simulation results

\begin{tabular}{ccccccc}
\hline Mode & $\mathrm{Q}_{\mathrm{L}}(\mathrm{w})$ & $\mathrm{Q}_{\mathrm{H}}(\mathrm{w})$ & $\mathrm{G}_{\mathrm{FL}}(\mathrm{kg} / \mathrm{h})$ & $\mathrm{G}_{\mathrm{FH}}(\mathrm{kg} / \mathrm{h})$ & $\mathrm{P}_{\mathrm{S}}(\mathrm{w})$ & EER \\
\hline CA mode 1 & 2800 & - & 1233.48 & - & 781.9 & 3.58 \\
\hline CA mode 2 & 13880 & - & 1233.48 & - & 3875 & 3.58 \\
\hline CA mode 3 & 4355 & - & 1233.48 & - & 1216 & 3.58 \\
\hline DCSTHIC mode 1 & 1000 & 1900 & 180 & 1126 & 614.18 & 4.72 \\
\hline DCSTHIC mode 2 & 2617 & 1900 & 180 & 1126 & 1053.64 & 4.287 \\
\hline DCSTHIC mode 3 & 2087.75 & 1900 & 180 & 1126 & 909.75 & 4.383 \\
\hline DCSTHIC mode 4 & 1118 & 3318 & 180 & 1306 & 901.76 & 4.919 \\
\hline
\end{tabular}

(1) The total energy consumption of the system increased with the fresh air volume in both the traditional AC system and the DCS-THIC AC system.

(2) The fresh air volume did not affect the EER of the traditional AC system but directly borne on that of the DCSTHIC AC system. This is attributable to the difference in airconditioning mode: the humidity control capacity of DCSTHIC AC increases with both the fresh air volume and the cooling load.

(3) For traditional AC system, the different modes differed in total power consumption but agreed on the EER, due to the use of the same cooling source. For the DCS-THIC AC system, the different modes had different total power consumption and different EERs. The difference is resulted from the disparity between the LTCS and HTCS. Specifically, Mode 4 had the highest EER for the DCS-THIC AC system.

(4) When both systems were operating in Mode 1, the DCSTHIC AC system consumed $24.5 \%$ fewer energy than the traditional AC system.

(5) When both systems were operating in Mode 2, the DCSTHIC AC system consumed $16.49 \%$ fewer energy than the traditional AC system.

(6) When both systems were operating in Mode 3, the DCSTHIC AC system consumed $18.32 \%$ fewer energy than the traditional AC system. This is because the DCS-THIC AC system needs only a few amount of fresh air to ensure personnel sanitation and humidity control, and has relaxed requirements on cooling source.

(7) When operating in Mode 4, the DCS-THIC AC system had a $12.23 \%$ greater EER than it was in Mode 3, due to the growth in HTCS load and decline of the LTCS load.

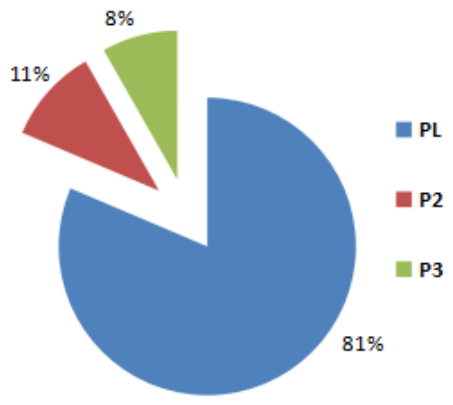

Figure 10. Energy consumption of traditional AC system in each mode

Figures 10 and 11 respectively display the energy consumption of both systems in each mode. It can be seen that the cooling source is the leading energy consumer in $\mathrm{AC}$ system. Since the DCS-THIC AC system is more complex than the traditional AC system, its pump and fan takes up a greater ratio in energy consumption than those in the traditional system. Moreover, the EER of the DCS-THIC AC system increased with the energy consumption of the HTCS.
Therefore, the HTCS must be fully utilized in the design of the DCS-THIC AC system, and set the return air volume properly to enhance the EER of the AC system.

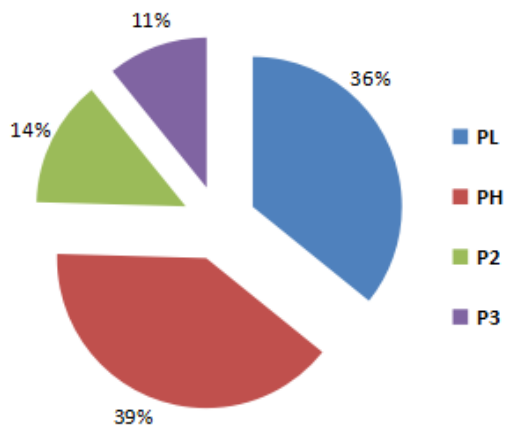

(a) Mode 1

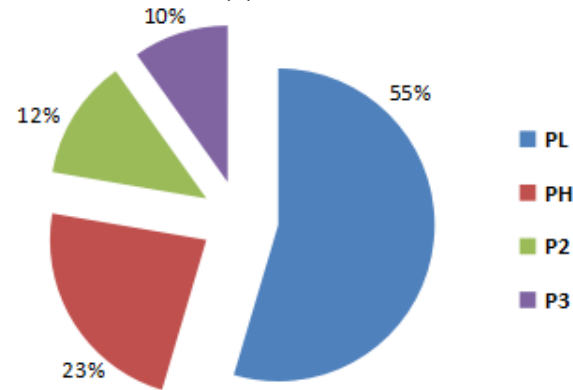

(b)Mode 2

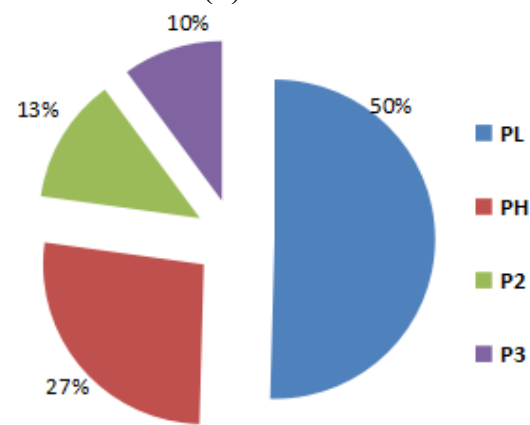

(c) Mode 3

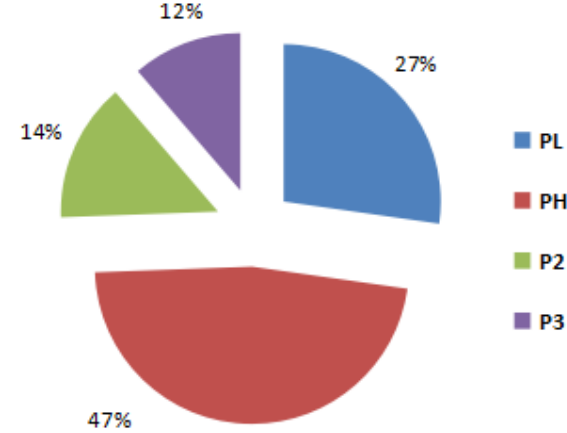

(d) Mode 4

Figure 11. Energy consumption of DCS-THIC AC system in each mode 


\section{CONCLUSIONS}

This paper experimentally investigates the performance of R236fa/R32 refrigerant mixture and applies it to the DCSTHIC AC system. The mixture outperforms the traditional refrigerants in COP and environmental friendliness. Then, the humidity control effect and fresh air volume of the DCS-THIC $\mathrm{AC}$ system in three operating modes were compared to the traditional AC system in three operating modes. The main conclusions are as follows:

First, the COP of R236fa/R32 refrigerant mixture peaks at 4.55 when the mass fraction of $\mathrm{R} 32$ reaches $60 \%$. In this case, the compressor power is minimized at $1.2 \mathrm{~kW}$ and the condensing and evaporating pressure is moderate. The only disadvantage is the soaring exhaust temperature. However, even the highest exhaust temperature is below $100^{\circ} \mathrm{C}$, which fulfils the requirements for the safe and stable operation of the compressor.

Second, the DCS-THIC AC system using R236fa/R32 $(0.4 / 0.6)$ refrigerator mixture saves more energy than the AC system using pure R22. Particularly, the energy efficiency can be improved by $27.22 \%$ by the DCS-THIC AC system in Mode 4.

Third, the traditional AC system requires minimum cooling if it has no fresh air mode. By contrast, the DCS-THIC AC system can elevate the energy efficiency ratio by properly increasing the fresh air volume. Hence, the fresh air volume should be increased properly in areas of small outdoor humidity.

\section{ACKNOWLEDGMENTS}

This work was supported by The 13th Five-Year National key research and development program of China (Grant No.2016YFC0700303). Heating and air conditioning solutions and corresponding systems in the Yangtze River Basin building.

\section{REFERENCES}

[1] Zhang T, Liu X, Jiang Y. (2014). Development of temperature and humidity independent control (THIC) air-conditioning systems in China-a review. Renewable \& Sustainable Energy Reviews 29(7): 793-803. https://doi.org/10.1016/j.rser.2013.09.017

[2] Gao ZH, Liu XH, Yi J. (2011). Experiment study on cooling capacity of capillary-tube radiation airconditioner. Acta Energiae Solaris Sinica 32(1): 101-106.

[3] Khan Y, Khare VR, Mathur J. (2015). Performance evaluation of radiant cooling system integrated with air system under different operational strategies. Energy \& Buildings $\quad 97$ : 118-128. https://doi.org/10.1016/j.enbuild.2015.03.030

[4] Si Q, Zhang XS. (2015). Performance evaluation and experimental study of the induction radiant airconditioning system. Procedia Engineering 121(3): 1795-1804. https://doi.org/10.1016/j.proeng.2015.09.159

[5] Li Z, Chen JB, Yu HZ, Cui LC. (2017). The development and experimental performance evaluation on a novel household variable refrigerant flow based temperature humidity independently controlled radiant air conditioning system. Applied Thermal Engineering 122: 245-252.

https://doi.org/10.1016/j.applthermaleng.2017.04.056

[6] Han X, Zhang X. (2011). Experimental study on a residential temperature-humidity separate control airconditioner. Energy \& Buildings 43(12): 3584-3591. https://doi.org/10.1016/j.enbuild.2011.09.029

[7] Chen Y, Yin YG, Zhang XS. (2014). Performance analysis of a hybrid air-conditioning system dehumidified by liquid desiccant with low temperature and low concentration. Energy and Buildings 77(77): 91102. https://doi.org/10.1016/j.enbuild.2014.03.050

[8] Zhao K, Liu XH, Zhang T, Jiang Y. (2011). Performance of temperature and humidity independent control airconditioning system in an office building. Energy and Buildings 43(8): 1895-1903. https://doi.org/10.1016/j.enbuild.2011.03.041

[9] Jeong J, Yamaguchi S, Saito K, Kawai S. (2010). Performance analysis of four-partition desiccant wheel and hybrid dehumidification air-conditioning system. International Journal of Refrigeration 33(3): 496-509. https://doi.org/10.1016/j.ijrefrig.2009.12.001

[10] Su W, Zhang XS. (2017). Thermodynamic analysis of a compression-absorption refrigeration air-conditioning system coupled with liquid desiccant dehumidification. Applied Thermal Engineering 115: 575-585. https://doi.org/10.1016/j.applthermaleng.2016.12.071

[11] Jiang Y, Ge TS, Wang RZ, Huang Y. (2013). Experimental investigation on a novel temperature and humidity independent control air conditioning system under heating condition. Proceedings of the 26th International Conference on Efficiency.

[12] Daou K, Wang RZ, Xia ZZ. (2006). Desiccant cooling air conditioning: A review. Renewable \& Sustainable $\begin{array}{lll}\text { Energy } & \text { Reviews } & \text { 10(2): }\end{array}$ https://doi.org/10.1016/j.rser.2004.09.010

[13] Mohan BS, Tiwari S, Maiya MP. (2015). Experimental investigations on performance of liquid desiccant-vapor compression hybrid air conditioner. Applied Thermal Engineering 77: 153-162. https://doi.org/10.1016/j.applthermaleng.2014.12.004

[14] Lowenstein A, Slayzak S, Kozubal E. (2006). A zero carry over liquid-desiccant air conditioner for solar applications. in: ASME 2006 International Solar Energy Conference. American Society of Mechanical Engineers 397-407. https://doi.org/10.1115/ISEC2006-99079

[15] Yang K, Yao Y, Liu S. (2012). Effect of applying ultrasonic on the regeneration of silica gel under different air conditions. International Journal of Thermal Sciences 61(61): 67-78. https://doi.org/10.1016/j.ijthermalsci.2012.06.007

[16] Yu PF, Zhang XS. (2014). Theoretical Study on the Variable Evaporating Temperature Refrigeration Performance of Non-azeotropic Refrigerant Mixtures. Building Science 30(12): 75-79.

[17] Yu PF, Zhang XS, Wen XT. (2017). Theoretical and experimental study on the heat transfer temperature difference based on the nonlinear temperature enthalpy of the R236faR32 mixtures. Procedia Engineering 205: 2126-2132. https://doi.org/10.1016/j.proeng.2017.10.136

[18] Yu PF, Zhang XS, Wen X. (2016). Determination method of condensing temperature and evaporation 
temperature for $\mathrm{R} 236 \mathrm{fa} / \mathrm{R} 32$ refrigeration system. Refrigeration and Air-conditioning 11: 38-42.

[19] Liu J, Zhang XS. (2015). Performance analysis of a novel double-temperature chilling water unit using large temperature glide zeotropic mixture. Procedia Engineering 121: 1222-1229. https://doi.org/10.1016/j.proeng.2015.09.145

[20] Liu J, She XH, Zhang XS, Man L, Zhou W. (2016). Experimental study of a novel double temperature chiller based on R32/R236fa. Energy Conversion and Management 124: 618-626. https://doi.org/10.1016/j.enconman.2016.06.023

[21] Liu J, She XH, Zhang XS, Cong L, Man L. Lindeman B, Lin T. (2016). Experimental and theoretical study on a novel double evaporating temperature chiller applied in THICS using R32/R236fa. International Journal of Refrigeration $75:$ $343-351$ https://doi.org/10.1016/j.ijrefrig.2016.08.015

[22] Hou DM, Wang C. (2012). Double cold sources temperature and humidity independent processing air conditioning system design. Heating Ventilating \& Air Conditioning 42: 100-104.

[23] Chen T, Yin Y, Zhang X. (2016). Applicability and energy efficiency of temperature and humidity independent control systems based on dual cooling sources. Energy \& Buildings 121: 22-31. https://doi.org/10.1016/j.enbuild.2016.04.001

[24] Yang CZ, Luo ZW, Jiang XB. Analysis of the system COP of different THIC air conditioning systems in Humid regions in summer season. Journal of Hunan University (Natural Sciences) 5: 144-150.

\section{NOMENCLATURE}

C Air specific heat $\left(\mathrm{KJ} /\left(\mathrm{Kg} \cdot{ }^{\circ} \mathrm{C}\right)\right)$

COP1 COP of the LTCS
COP2 COP of the HTCS

d Humidity ratio $(\mathrm{g} / \mathrm{kg})$

EER Energy efficiency ratio

$\mathrm{G}_{\mathrm{FL}} \quad$ Air rate processed by the LTCS $(\mathrm{kg} / \mathrm{h})$

$\mathrm{G}_{\mathrm{FH}} \quad$ Air rate processed by the HTCS $(\mathrm{kg} / \mathrm{h})$

$\mathrm{G}_{\mathrm{L}} \quad$ Air rate processed by the LTCS $(\mathrm{kg} / \mathrm{h})$

HTCS High-temperature cooling source

i Enthalpy of air $(\mathrm{kJ} / \mathrm{kg})$

LTCS Low-temperature cooling source

$\mathrm{N} \quad$ Indoor air state

$\mathrm{P} \quad$ Saturated vapor pressure (MPa)

$\mathrm{P}_{1} \quad$ Energy consumption from cooling source $(\mathrm{kW})$

$\mathrm{P}_{2} \quad$ Energy consumption from pumps $(\mathrm{kW})$

$\mathrm{P}_{3} \quad$ Energy consumption from fans $(\mathrm{kW})$

$\mathrm{P}_{\mathrm{C}} \quad$ Compressor power $(\mathrm{kW})$

$\mathrm{P}_{\mathrm{H}} \quad$ Energy consumption from HTCS $(\mathrm{kW})$

$\mathrm{P}_{\mathrm{K}} \quad$ Condensing pressure (MPa)

$\mathrm{P}_{\mathrm{L}} \quad$ Energy consumption from LTCS $(\mathrm{kW})$

$\mathrm{P}_{\mathrm{S}} \quad$ Energy consumption from air conditioning $(\mathrm{kW})$

$\mathrm{P}_{\mathrm{Z}} \quad$ Vaporization pressure (MPa)

Q Total refrigeration capacity $(\mathrm{kW})$

$\mathrm{Q}_{\mathrm{F}} \quad$ Fresh air load (kW)

$\mathrm{Q}_{\mathrm{FL}} \quad$ Fresh air latent load $(\mathrm{kW})$

$\mathrm{Q}_{\mathrm{FS}} \quad$ Fresh air sensible load $(\mathrm{kW})$

$\mathrm{Q}_{\mathrm{H}} \quad$ Load processed by the HTCS (kW)

$\mathrm{Q}_{\mathrm{IL}} \quad$ Indoor latent load $(\mathrm{kW})$

QIS Indoor sensible load ( $\mathrm{kW})$

$\mathrm{Q}_{\mathrm{L}} \quad$ Load processed by the LTCS $(\mathrm{kW})$

Qxs $\quad$ Sensible load processed by the LTCS (kW)

QYL Precooling fresh air rate by the HTCS $(\mathrm{kW})$

$\mathrm{T} \quad$ Temperature $\left({ }^{\circ} \mathrm{C}\right)$

W Fresh air state

$\omega \quad$ Indoor moisture load $(\mathrm{g} / \mathrm{h})$

$\varepsilon \quad$ Heat moisture ratio $(\mathrm{kJ} / \mathrm{kg})$

$\rho \quad$ density of water $\left(\mathrm{kg} / \mathrm{m}^{3}\right)$ 